\title{
What does it mean to explain language change? Usage-based perspectives on causal and intentional approaches to linguistic diachrony, or: On S- curves, invisible hands, and speaker creativity
}

\begin{abstract}
The question how language change should be explained has been intensely debated in linguistic research, and causal and intentional - or in Coseriu's terms, final - approaches have been proposed as the two basic options that are possible here (cf. Coseriu 1958). I will therefore start by critically reviewing the legitimacy and potential of conceiving language change in causal terms. In a next step I will turn to intentional explanations, which have been proposed as the second fundamental type of approach, and then investigate whether the controversy about causal vs. intentional explanations of language change can be resolved by assuming different mechanisms and types of explanation for the stages of innovation and propagation respectively, as proposed by Keller and Croft. In these reflections key assumptions of Cognitive Linguistics, more specifically of usage-based approaches to language and language change (Barlow/Kemmer 2000), will serve as a constant guideline, as they provide helpful criteria to judge the adequacy of explanations that have been previously proposed. Finally I will discuss the perspectives offered by usage-based approaches for explaining language change by outlining fundamental motors of change as well as their interplay in cognition and communication.
\end{abstract}

\section{Introduction}

The issue of explaining language change is one of the key issues in historical linguistics and beyond, and there has been a longstanding debate about the question how language change should be explained, i.e. what should count as a valid explanation of change. Two major types of explanation have been opposed in this context, which are often labeled as causal vs. intentional explanations, and which are often presented as being incompatible. Thus, two key questions arise here: 1) Can and should language change be explained by causal factors? Is this methodologically possible, and is a causal approach adequate in principle? And, especially if the answers to these questions are negative, 2) can intentional accounts be considered to be true explanations of change (what is frequently denied by the proponents of a causal approach), and may they therefore represent a more adequate approach to the study of language change instead? I will critically discuss both types of accounts and, in a next step, turn to two recent approaches which have proposed to combine different explanatory mechanisms within a comprehensive framework (Keller 1994 and Croft 2000). For these approaches, the question is raised whether such a synthesis is possible and whether it provides a better understanding of language change as a complex process. At the same time, I will analyze to what extent basic principles of usage-based approaches are followed by the authors, and the usage-based perspective will serve as a constant guideline for our reflections in this paper. Finally, I will conclude by reflecting upon the potential offered by approaches which are consistently oriented towards the level of the individual speakers and their linguistic activity in order to explain processes of language change. 


\section{Causal explanations - the only true type of explanations?}

Causal explanations represent in a certain sense the prototype of scientific explanations. This becomes especially clear in an interdisciplinary perspective, as in many cases, the term 'explanation' just means causal explanation, the most classical field of investigation probably being physical laws which presuppose causality relations.

Moreover, from a historical perspective, the 19th century and biology play a decisive role in shaping the notion of historical explanations. The insights gained by evolutionary biology have strongly influenced other sciences, and it was a central aim of 19th century linguistics to explain the structures of contemporary language by tracing it back to historical developments in an analogous way to evolutionary explanations in biology (cf. Engels 2007 for the success of evolutionary biological reasoning in other domains and disciplines). In this spirit, causal explanations of the evolution of language have been proposed. And even if certain applications of this evolutionary framework to the study of language change have been criticized for being too radical (e.g. Schleicher), this line of reasoning does not only persist in current research, but has even been strengthened in the biolinguistic approaches which have been proposed since Lenneberg's Biological foundations of language (1967) and especially in the last decade (cf. the journal Biolinguistics published since 2007 and edited by Cedric Boeckx/Kleanthes K. Grohmann; cf. also Newmeyer 1991; Jenkins 2000; 2004; Givón 2002; Chomsky 2004; 2005; Piattelli-Palmarini/Uriagereka/Salaburu 2009; Di Sciullo et al. 2010; Di Sciullo/Boeckx 2011). ${ }^{1}$

Quantitative investigations of language change have also fostered the quest for causal explanations. An example showing the appeal of approaches that identify general patterns of linguistic evolution is the enormous success of the S-curve model (see e.g. Croft 2000). In this model, which is, basically, the application of a mathematical sigmoid function to language, the diffusion of innovations follows an S-curve pattern: at first, innovations diffuse only slowly, in a second stage the speed of diffusion increases, and finally the speed of diffusion tapers again on its way to complete implementation in the population of individuals $(100 \%$ of the individuals having adopted the innovation). Originally developed by Rogers in a sociological study on the diffusion of agricultural innovations (Rogers 1995 [1962]), it has become a widely accepted, if not the standard model to describe and predict the diffusion of linguistic innovations, as illustrated by studies on syntactic change (Kroch 1989) and sound change in progress (Johnson 1976). However, several points remain critical here, and only little empirical evidence for the validity of the S-curve hypothesis has been provided. The "confirmations" of Rogers' model are based on very scarce data sets (e.g. Kroch discusses studies by Oliveira/Silva, Fontaine and Priestly based on only four to seven data points; cf. Kroch 1989), and in Johnson's data, the third stage of diffusion was not attested, so the Scurve hypothesis is not fully confirmed by his study.

Moreover, basic methodological issues arise (cf. Winter-Froemel 2011: 140-147; 2012). For example, the S-curve hypothesis presupposes that the group of individuals (in which the innovation diffuses) remains constant, as it is the case in Rogers' example of a group of farmers who progressively adopt a new production technique. In the domain of linguistics, however, this requirement is hard to meet with historical corpora, as the texts documented in the corpora have been produced by different generations of speakers, and the various tranches

1 And even if Schleicher's views have often been criticized, it seems interesting to observe that quite similar stances are taken in Chomsky's early work as well as in the paradigm of biolinguistics. 
of corpora (e.g. texts from 1800-1849, 1850 to $1899,1900-1949$ etc. $^{2}$ ) are not fully comparable in this sense: In order to evaluate the diffusion of an innovation at different stages of its propagation in the speech community, we would have to assume that the texts contained in the various tranches are fully representative of the linguistic usage of each period, that is, perfectly balanced corpora would be needed - however, corpora meeting this requirement are not available. ${ }^{3}$ Moreover, even if fully balanced corpora were at hand, one might still object that we cannot fully compare the linguistic usage of different periods of time, as there might be fundamental cultural and historical differences which might act upon the usage of the various periods. For example, And even if this problem can be partly attenuated by opting for more fine-grained analyses, based on thinner time tranches, it still seems to a certain degree problematic to directly compare the data of e.g. Middle English from 1440 to 1460 to the data of Early Modern English from 1580 to 1600 etc. (cf. Ellegård's and Kroch's analysis of the evolution of English periphrastic do; Kroch 1989: 228). ${ }^{4}$

Further problems arise with the interpretation of frequencies provided by the corpus data. Corpus frequencies cannot be simply equated with a certain number of speakers having adopted the innovation. Instead, single uses of a certain form in the corpus data could also be nonce uses that do not correspond to a stable active and regular use of the innovation by the individual speakers. Another problem is that we cannot define an upper bound $(100 \%=$ complete implementation) for lexical innovations taken in isolation. However, the S-curve model presupposes the existence of an upper bound, and its application to lexical change thus faces very principled problems. At least to my knowledge, all these basic issues have not been critically discussed up to now, and the enormous success of the S-curve hypothesis in linguistics may thus seem surprising. What seems to account for its enormous success, however, is the fact that it adopts a quantitative perspective and proposes to trace back the complex process of the diffusion of an innovation to a simple pattern that can be mathematically described.

From a more general perspective, we may observe that behind this openness towards mathematical and evolutionary models of language change lies a certain conception of linguistics compared to other sciences (cf. Coseriu 1958: 101). There is thus a fundamental question of the philosophy of science at stake here: Is linguistics part of the (natural) sciences, or is it part of the humanities, and consequently, should the evolution of language be explained according to the same principles and mechanisms as processes of evolution in other domains, or do we have to assume that fundamentally different mechanisms are at work (cf.

2 Kroch bases some of his statistical analyses on even larger tranches of time, namely on whole centuries (Kroch 1989).

3 This point is very clearly put forward in Labov's definition of historical linguistics as "the art of making the best use of bad data" (Labov 2010 [1994]: 11), which is motivated by the observation that "(h)istorical documents survive by chance, not by design, and the selection that is available is the product of an unpredictable series of historical accidents. The linguistic forms in such documents are often distinct from the vernacular of the writers, and instead reflect efforts to capture a normative dialect that never was any speaker's native language. As a result, many documents are riddled with the effects of hypercorrection, dialect mixture, and scribal error. Furthermore, historical documents can only provide positive evidence. Negative evidence about what is ungrammatical can only be inferred from obvious gaps in distribution, and when the surviving materials are fragmentary, these gaps are most likely the result of chance." (Labov 2010 [1994]: 11; cf. also Fleischer/Simon 2013: 3).

4 Moreover, if we opt for too fine-grained analyses, we will in many cases obtain zig-zag-patterns which no longer resemble an S-curve (at least, not intuitively). At least to my knowledge, the basic methodological issue of determining what would be reasonably dimensioned time spans and time tranches for statistical analyses of historical data has not yet been addressed in previous studies. 
Itkonen 2011: 22-25)? This question was debated by Schleicher, who mainly argues that linguistics is a natural science; however, what has been perceived less clearly is that he also recognizes certain differences between linguistic evolution and biological evolution (cf. Schleicher 1863: 29), as more recent approaches claiming a generalized evolutionary theory stress more explicitly (cf. Müller 1990; Hull 1988; Croft 2000). The authors who work within the biolinguistic paradigm, in contrast, clearly emphasize their orientation towards the natural sciences.

In this debate about the legitimacy of studying language according to methods of the natural sciences, strong judgments are (mostly implicitly) present. Natural sciences and the humanities are not considered equal; in fact, natural sciences are considered to be the prototypical sciences, while the humanities represent at most a weaker kind of scholarship, and there is a tendency to assume that the "true" and important scientific questions and methods are those of the natural sciences. Thus, from the perspective of the philosophy of science, an important motivation for the approaches proposing to attribute language change to causal mechanisms and to study it according to methods of the natural sciences seems to be the attempt to increase the importance of linguistics as a discipline (cf. Coseriu 1958: 101).

A very important feature in this context is predictability, which translates into repeatability of experiments when testing a certain hypothesis. For example, basic principles of physics such as classical mechanics and the force of gravitation can be illustrated again and again by striking a billiard ball with the cue stick or by dropping an apple (cf. also Itkonen's description of deterministic explanations, see Itkonen, this volume). Yet a similar kind of repeatability is not given in cases of historical processes of evolution even in the domain of physics, and in a general manner, the ceteris paribus assumption represents an important challenge in this context, i.e. the effect of a certain cause can only be predicted if the experiments are run under the same circumstances and all potentially interfering factors are ruled out. Methodologically, however, this criterion is hard to meet, as the interfering factors may be still unknown, so that it can prove difficult to control for what is still unidentified.

Concerning the domain of language and language change, the notion of predictability is especially problematic, as we can frequently observe that a certain development taking place in one language does not occur in another. An example for this would be the development of the French impersonal on compared to German man, where both pronouns originate from a lexical item meaning PERSON or MAN (German man/Latin homo) and develop an impersonal meaning, but the further shift to a $1^{\text {st }}$ person plural meaning that has occurred in spoken French has not taken place in German man (cf. Winter-Froemel/Zirker 2010: 84-86; WinterFroemel, in press b). In other cases, we can observe diverging pathways of evolution, as can be seen in the semantic evolution of West Germanic *knehta- developing into a socially higher vs. lower meaning in English (knight) and German (Knecht 'servant'), respectively (cf. OED, EWDS). Another example that can be given here is the evolution of English while from temporal to adversative meaning compared to German weil, which develops a causal meaning (cf. Traugott/König 1991: 199-203; Keller 1995: 27; Detges 2001: 40-44; for further examples and general theoretical reflections on the comparison of processes of language change in different speech communities cf. Fleischer/Simon 2013). Of course this could be due to the fact that the conditions are not exactly the same in both speech communities, and the main problem would thus be to identify all the relevant factors of change and conservatism in both speech communities respectively. Nevertheless, it must be admitted that in language change there is a very intricate interplay of factors at work (cf. Farrar's remarks on 'multicausation' of processes of language change; Farrar 1999: 28). The conditions and 
circumstances for a potential process of change in two speech communities and/or at two different stages of time will never be exactly the same. Sociolinguistic variables provide potential factors that may explain certain differences between speech communities, but further factors intervene here, e.g. concerning the possible paths of diffusion of an innovation, such as the structure of the social network in the speech community, etc. (cf. Enfield 2003).

In addition, for individual processes of language change, there may be further specific factors which can appear quite random. This means that there is a complex set of factors, and as the factors of change interact with each other, it seems highly questionable or even practically impossible that we will ever manage to make "hard" predictions, every initial situation being specific and different from what has been observed before. Accordingly, many previous approaches to language change have stressed that it is impossible to predict language change (cf. Itkonen 2003: 7); what we can at most achieve is to identify certain tendencies and pathways of change (representing probable ways of evolution, cf. e.g. Traugott/Dasher 2002, Heine/Kuteva 2002). ${ }^{5}$

\section{Intentional explanations - the second basic option?}

Beyond the observations made above, it seems important to note that from a historical perspective, the "modern" type of causal explanations is just one type of explanation besides others. Aristotle has distinguished four possible types of causes, or four ways to reflect on the "why" of a certain object: the formal, efficient, final ${ }^{6}$ and material cause (Aristotle, Physics; cf. Coseriu 1958: 113-114; Falcon 2012):

It is clear then that there are causes, and that the number of them is what we have stated. The number is the same as that of the things comprehended under the question 'why'. The 'why' is referred ultimately either (1), in things which do not involve motion, e.g. in mathematics, to the 'what' (to the definition of 'straight line' or 'commensurable', \&c.) [causa formalis/the formal cause, EWF], or (2) to what initiated a motion, e.g. 'why did they go to war?-because there had been a raid' [causa efficiens/the efficient cause, EWF]; or (3) we are inquiring 'for the sake of what?' - 'that they may rule' [causa finalis/the final cause, EWF]; or (4), in the case of things that come into being, we are looking for the matter [causa materialis/the material cause, EWF]. The causes, therefore, are these and so many in number. (Aristotle, Physics II,7)

First of all, it seems interesting to observe that we find here four types of causes, while later studies have only retained two of these causes, in order to define two basic options how to approach language change. The efficient cause ("the primary source of the change or coming to rest", Physics, II,3) identifies what we would today simply label as "cause" (so this corresponds to the notion of causal explanation discussed above). Aristotle himself attributes a special status to the efficient cause with respect to the explanation of processes in which

5 Nevertheless, this basic limitation is obscured by the impression that we can get from prior studies showing that certain processes of change follow well-known pathways of evolution. Yet the explanations offered here are only ex post explanations: the studies are simply based on the observation that the change has already occurred, and what is completely passed over here is the possibility that the change may have not occurred. That is, the important question of explaining not only change, but also continuity (why languages or certain structures in language do not change) essentially remains open in most studies.

6 The expression 'final' is understood here in the sense of the Latin term, as referring to the purpose or aim of an action; many linguistic approaches, in contrast, prefer the term 'intentional' instead in order to refer to this aspect. In this paper I will use both terms interchangeably. 
new entities are created. ${ }^{7}$ Nevertheless the basic question remains whether language change is most adequately subsumed under this group of objects, and some approaches have argued that we should focus on final cause instead (cf. Coseriu 1958). According to Aristotle's systematics, the final cause describes the purpose for which an object is created ("'that for the sake of which' a thing is done", Physics, II,3), and it has been identified as being also potentially relevant to explaining language change, as it relates to the motives and intentions the speakers want to pursue in their communicative interactions.

Two main questions arise here: First, what about the other two types of causes? And second, do the basic types of causes necessarily imply contradictory or mutually exclusive approaches to language change?

Let us start by addressing the first question. In fact, the other two types of causes also prove to be potentially relevant to the study of language and language change. Material cause is defined by Aristotle as the material out of which a certain object is made ("that out of which a thing comes to be and which persists", Physics, II,3). Applied to the study of language, this type of cause could be related to the material realization of the speakers' utterances, more precisely to the phonic and graphic strings, and more generally to the alternative between phonic and graphic realizations, which proves important for explaining specific processes of change, e.g. in cases of spelling pronunciation and in cases of loanword adaptation based on the graphic vs. phonic realization of the source language item (e.g. the English word people has been borrowed into French in two different variants, people and pipole, where the former variant is derived from the English spelling, while the latter variant is based upon the - partly adapted - pronunciation of the loanword in French; cf. WinterFroemel 2010).

The formal cause, in contrast, defines the way in which a certain object is arranged (what makes it a valid instantiation of the idea that precedes it - "the form or the archetype", Physics, II,3). However, Aristotle points out that the formal and the final cause frequently coincide ("the 'what' and 'that for the sake of which' are one", Physics, II,7), and consequently he reduces the why-question to three main types of answers. This means that for Aristotle, formal and final causes are closely related or even inseparable. This idea can also be applied to the domain of language and language change: If the speaker forms his/her utterance in a certain way in order to fulfill specific purposes in communication, the structure of the utterance can be identified as the formal cause in the sense of Aristotle, and investigations of individual processes of language change are concerned not only with the motives guiding the speakers, but also with the linguistic structures themselves. Using different labels, we could treat the linguistic structures as a possible explanandum, and the speakers' intentions etc. as a possible explanans, addressing the question why speakers should have introduced or adopted a certain way of expressing a given content.

In addition, the material cause identifies another aspect that is relevant to linguistic innovation and change. Grounded on the basic semiotic alternative between actual and virtual semiotic entities (or concrete vs. potential entities; cf. Saussure 1969 [1916]; Coseriu 1955-56; Hilty 1971; Blank 1997: 101; Winter-Froemel 2011: 255; Winter-Froemel, in press a), we can

\footnotetext{
"The question 'why', then, is answered by reference to the matter, to the form, and to the primary moving cause. For in respect of coming to be it is mostly in this last way that causes are investigated - 'what comes to be after what? what was the primary agent or patient?' and so at each step of the series." (Aristotle, Physics II,7).
} 
say that material cause aims at the concrete realization of the utterance, and formal cause, in contrast, to the abstract linguistic structure or pattern.

The individual utterances could also be interpreted as an explanans that accounts for changes in the language system, as one of the central claims of usage-based approaches is precisely that the structures of language are shaped by single discourse events. In a causal approach, however, such an analysis would lead to the task of determining the causes which have given rise to the utterances, namely the cognitive processes located in the speakers' minds which have led the speakers to formulating their utterances in a certain way. In a final approach, this latter aspect would be immediately addressed, as the concept of finality cannot be applied to the utterances themselves - sentences do not themselves intend anything, they can only embody the intentions of their speakers. Consequently, the focus is on the speakers instead who have certain intentions and pursue certain strategies.

Both the material and the formal cause thus play a role in language change, but they do not represent causes in the same sense as efficient and final causes do. Both material and formal cause refer to the structures of language (on a concrete and on an abstract level), while efficient and final causes address inherently dynamic aspects, namely the ways in which language is shaped by the speakers' linguistic activity (the choices they make when formulating their utterances and interpreting the utterances of others). We can also think here of the terms ergon vs. energeia, which were originally coined by Humboldt. These terms represent one of the basic sets of alternatives on which Coseriu develops and defines his own approach as an approach focused on language as a creative activity in the sense of the latter term energeia (Coseriu 1958: 25). This conception thus characterizes a specific approach to study the "why" of language change, namely an approach which asks for the purpose of the individual linguistic items and structures (i.e. language as an ergon) from the perspective of the speakers who actively use and shape them (energeia).

This leaves us with the basic choice between causal and final approaches. The first problem which needs to be addressed here concerns terminology. As I have stated above (see note 6), the terms 'final' and 'intentional' will be used interchangeably in this paper. However, the intentional/final type of explanation has also been discussed under the label of teleological explanation in previous research (e.g. Lass 1980; cf. Winter-Froemel 2008, 2011). This appears to be more problematic, as these terms are not strictly synonymous. The term 'teleological' also relates to finality, however it makes the strong claim that the linguistic structures observed directly match the intentions pursued by the individuals who initiated their use. In this sense, the teleological approach would predict that language change, in the long run, will lead to a "better" overall structure of the language system, because the speakers use structures that they judge "better" than the existing structures. 'Intentional/final' approaches, in contrast, are based on the weaker assumption that the fact that languages change can be explained by the speakers' purposeful use of language. This means that the concept of intentionality is only referred to at the level of the speakers' individual utterances in concrete situations of speaker-hearer interaction, but not at the level of the overall structures of language. An intentional/final approach thus leaves open the possibility that the eventual structures of language will not directly match the speakers' original intentions. It seems central to insist on this point, as we are dealing here with an issue where there have been, and still are, basic misunderstandings arising from the frequent confusion of teleological and intentional/final aspects. Coseriu's (1958) and Keller's (1994) approaches to language change are important contributions to this discussion, as they insist that we can identify intentional aspects of language change without claiming that the structures of language 
directly match these intentions, i.e. they claim a (partly) final account of language change, but explicitly (and more or less sharply) reject a teleological approach.

A very demonstrative pattern of evolution in this respect is the pattern of Mandeville's paradox that can be observed in certain cases of language change. These cases are lengthily discussed by Keller (1994) and can thus be seen as good examples for his invisible hand approach to language change (cf. section 4 below). According to Keller, they are characterized by the fact that in the long term, language change runs counter to the intentions of the individual speakers introducing the innovations. For example, in Middle High German, we can observe frequent uses of the form vrouwe meaning 'noble woman' which can be explained by the speakers' intention to make their utterances appear to be very polite, distinguished etc. However, more and more speakers following this strategy, the form continuously loses this meaning and becomes the neutral expression for FEMALE PERSON (cf. Keller 1994: 107-109), that is, the speakers follow a strategy "Praise her", but language change goes in the opposite direction, making the form become a neutral or even pejorative choice ("Blame her", cf. also the semantic evolution of German Weib from a neutral to a clearly pejorative meaning). ${ }^{8}$ This means that the innovation is explained by speaker strategies and intentions, but we clearly have no teleological evolution of language here.

It seems interesting to note that Keller mainly focuses on striking examples of Mandeville's paradox in which the additional pragmatic effects conveyed by the innovations by virtue of their new and marginal status become progressively weakened in the course of diffusion, and semantic change takes place. It appears to me that these cases are an instantiation of a more general pattern in language change, namely cyclic patterns of evolution. These can be illustrated by the evolution of French aujourd'hui. The first step in this change is a formal reduction, motivated by cognitive ease/reducing processing efforts, namely the phonological change of Latin hodie 'today' into Old French hui. This change leads to an item that might have been felt as being too short, so that speakers have introduced the new expression aujourd'hui, literally 'on the day of today' in order to have a longer and in this sense, clearer form again (cf. Lüdtke 1980; Keller 147-155). Originally a paraphrase, this expression has become fully lexicalized, and in contemporary French we can thus find the striking new paraphrase "au jour d'aujourd'hui", which means etymologically 'on the day of [on the day of today]'. This example illustrates the inherent antagonism of principles and maxims oriented towards the speaker and his/her processing efforts on the one hand and principles and maxims oriented towards communicative success, expressivity etc., on the other hand (cf. section 4).

Now let us come back to the question if causal and intentional/final accounts are necessarily incompatible. It seems important to note that what is put forward in approaches investigating intentional/final mechanisms of language change is the speakers' ability to actively shape their utterances and by doing this, ultimately (re-)shape language. In causal approaches, in contrast, the main aim is to study general external factors which determine the speaker's behaviour and of which s/he is probably not even aware. So in the end, the debate about the legitimacy and adequacy of causal vs. intentional/final explanations of language change also touches upon the basic issue of the existence (or nonexistence) of free will. If we

8 In the semantic evolution of vrouwe/Frau, two aspects can be distinguished: First, the additional positive pragmatic value of the expression progressively disappears, the form becoming the neutral term (vrouwe 'noble woman' $\rightarrow$ 'woman'); second, this form even acquires a slightly negative interpretation compared to new forms with an additional positive value (G. Dame). 
assume that language change can be fully explained by causal mechanisms, we should theoretically be able to predict the individual developments (even if this may be difficult from a methodological perspective, cf. the remarks made above), and this means that we assume that the speakers' choice of a certain linguistic item is entirely determined by a (albeit complex) interplay of factors. If, in contrast, we assume that the speakers have a certain liberty to shape their utterances by selecting or creating certain forms of expression (e.g. new forms) and by discarding others, there is at least a certain degree of liberty in the speakers' behaviour.

The issue of determinism certainly cannot be resolved here. Nevertheless, it seems possible to continue our reflections assuming that the question of determinism may also depend on the level of investigation which is chosen. Studying neuronal processes, we may discover deterministic components, but nevertheless it seems reasonable to claim that there is a certain degree of liberty in the speakers' actions, as this is also the way the speakers themselves perceive their linguistic activity, for example when pondering the adequacy of one expression compared to another when writing a formal letter etc. Usage-based approaches may serve as a theoretical underpinning to the latter perspective, as they stress the legitimacy and importance of focusing on language and language use as it is perceived by the speakers (I will return to this issue in section 5 below).

Summing up, we can identify two basic factors that are potentially relevant to explaining language change in general. One of these seems to correspond to the prototypical understanding of an explanatory factor, namely the efficient cause or causal factor, while the other one - final cause - identifies an aspect for which it is not so much its role in language change which seems controversial, but rather its explanatory value. The causal type of explanation is closely related to predictability, which remains controversial or at least methodologically difficult to achieve for language change. At the same time we have seen that causal and intentional/final explanations might not necessarily represent two mutually exclusive approaches to the study of language change. In the following section, I will therefore discuss two approaches which have proposed to distinguish two basic types of explanation, and to combine them by relating them to different stages of language change (Croft), or to two levels of analysis (Keller), respectively.

\section{Approaches combining causal and intentional mechanisms in a comprehensive framework}

Keller's approach to language change is grounded on the notion of "the invisible hand". This concept underlines a feature that Keller considers to be central to language and "normal" language change (i.e. language change which does not involve language planning): Looking at changes in the structures of a certain language, we can get the impression that they have originated from the action of an invisible creator; however, the individual speakers who have brought about the change are normally not aware of having contributed to initiate or foster a certain process of change. ${ }^{9}$ One of the key elements in this approach to language change is thus the distinction of two levels of analysis: on the one hand, there is the micro-level of the

9 "An [invisible-hand, EWF] explanation can generally be characterised as follows: it must show how the communicating individuals' efforts, which are designed to fulfil their own communicative purposes and not to cause language change, lead or must lead to the structure to be explained, thereby taking into consideration the ecological conditions under which people act." (Keller 1995: 25). 
intentional actions performed by the speakers, and on the other hand, there is the macro-level of the global consequences of these actions, brought about by causal mechanisms. Therefore, Keller argues, neither intentional nor causal explanations taken alone are sufficient to explain language change, but it is only taken together that they permit us to account for the entire process of change. ${ }^{10}$

For the micro-level, Keller further identifies two major forces which continuously guide the speakers in their linguistic activity: these are the static and the dynamic maxims, which can be summed up as "Speak like the others." vs. "Speak in such a manner that you get noticed." (i.e. "Do not speak like the others.", EWF) (Keller 1994: 137 and 139). Obviously, these principles contradict each other, and the dynamic potential arising here opens up the possibility of innovations that might lead to a change in the language, if they are adopted by a sufficiently large number of speakers. According to Keller, it is the static maxims that account for homogeneity and stasis, whereas the dynamic maxims explain processes of language change. Although intuitively this correlation seems very clear, there are certain cases of language change which are more complex and therefore have to be explained differently. For example, in situations of language contact, the principle "Speak like the others." can be referred to either the group of the source language speakers or the group of the target language speakers, potentially fostering the introduction of a borrowing into the target language (i.e. fostering change) or, in contrast, favouring the conventional target language way of expressing the concept (i.e. fostering conservatism). An analogous reasoning is possible for the dynamic maxims (cf. Winter-Froemel 2011: 171-172), and this refinement of Keller's approach seems necessary whenever language change involves a borrowing of a certain expression from another group of speakers, i.e. not only for situations of borrowing between historical languages, but also for cases of borrowing between different varieties of a historical language.

For the process of diffusion on the macro-level, Keller only assumes one basic principle, namely that we are dealing with a cumulative process. However, certain refinements prove necessary here as well. In fact, within Keller's own approach, we can detect a fundamental qualitative change concerning the status of the innovation in the course of diffusion: Whereas at a first stage, the innovation is marginal and its use thus can be explained by the speaker's choice to give priority to the dynamic principle (i.e. use of the non-conventional form $=$ innovation), from the moment on when $50 \%$ of the speakers of the speech community have adopted the innovation, the dynamic principle would lead the speakers to using the older form, which means that it is now the static maxims that account for the adoption of the innovation by the rest of the speech community. We have thus a fundamental qualitative change of the value of the innovation in the course of its diffusion; however, this change is not commented on by Keller (cf. Winter-Froemel 2011: 157-158). ${ }^{11}$

10 Keller rejects the label 'final'/'finalistic' and uses the labels 'intentional' vs. 'causal' to characterize and oppose the two basic types of explanation. He comments on this use in a footnote stating that finalistic explanations always imply a forward perspective, while intentional explanations can also adopt a backward perspective (Keller 1994: 112). It seems to me, however, that these limitations do not necessarily hold, and I will analyze here Keller's reasoning concerning intentional aspects together with other approaches oriented to intentional/final mechanisms of language change.

11 This kind of reasoning presupposes that the innovation competes with a conventional way of expressing the same content. In the domain of lexical change, however, this assumption only holds for certain kinds of innovations, whereas there are also fundamentally different cases in which new words are introduced in order to designate new concepts. Systematically distinguishing between these two basic alternatives, which can be labelled 'catachrestic ( necessary)' vs. 'non-catachrestic ( luxury) innovations' (cf. Onysko/Winter- 
Moreover, the cumulative interpretation of the diffusion process proposed by Keller neglects an important difference between language change and other instantiations of invisible hand processes: While in the case of traffic jams arising "from nothing" or in the case of bystanders watching street artists and forming circles in front of Centre Pompidou, Paris (cf. Keller 1994: 34-35), the individuals' actions are more or less independent from each other ${ }^{12}$, this is clearly not the case in language. The principle of alterity implies that linguistic activity always involves a direct interaction with the hearer, and when choosing how to formulate his/her utterance, the speaker always takes into account the perspective of the hearer, his/her (expected) linguistic and contextual knowledge, attitudes, expectations etc. (cf. Coseriu 1958; 1983: 56; Oesterreicher 1979: 230; 1988: 363-364; Kabatek 1996: 7; Schlieben-Lange 2010; Koch/Oesterreicher 1990, 15; Keller 1994: 201-202). In this sense, the introduction of an innovation is fundamentally different from the re-use of an element that other speakers have used before, as it requires a fundamentally different cognitive processing by the hearer, and the innovations acquire a specific social value, as Croft (2000) emphasizes very clearly. More specifically, it is insufficient to assume an either-or distinction between completely new linguistic entities (innovations) and completely conventionalized entities (elements of the language system), as the process of diffusion is precisely characterized by an intermediate status of the newly introduced items, which pass from very marginal to weakly marginal items before becoming fully conventionalized. This means that the innovations are differently perceived at various stages of diffusion. Recent research suggests that a marginal status of linguistic items systematically triggers additional pragmatic interpretations (cf. Levinson's Theory of Presumptive Meanings; Levinson 2000: 137; cf. Onysko/WinterFroemel 2011); however, up to now the qualitative changes in the perception of innovations in the course of their diffusion have not been systematically studied (cf. Winter-Froemel 2011: 282-288).

This leads us to another, even more fundamental issue: Keller's reasoning about the speakers' intentions is exclusively applied to the stage of innovation, whereas he describes diffusion as a global process, and he extensively dwells on the necessity and regularity with which this process takes place, emphasizing that it follows general laws which are beyond the individual speakers' reach. This can be seen as an attempt to approximate linguistics partly to the natural sciences (cf. our remarks on the attraction of similar approaches in section 2). Is Keller right in claiming that processes of language change involve a stage of diffusion which implies a causal type of explanation (the parallel actions of a sufficiently large number of individual speakers inevitably triggering a change in the language system)?

Several potentially problematic issues are raised here. First, Keller's explanation mode faces the danger of circularity, that is, of mere storytelling like in the case of Kipling's poetic Just-so stories (Kipling 1987 [1902]; cf. Winter-Froemel 2011: 152-177; see also Fleischer/Simon 2013: 6). Moreover, analyses of language change normally adopt an ex post perspective, as the changes studied have already occurred, and in this sense it seems trivial to state that the language has changed in a certain respect because the majority of the speakers have decided to use a new item. In a certain respect, this observation is certainly correct, but

Froemel 2011; Winter-Froemel 2011: 309-315), opens up the possibility to make further refinements to Keller's approach.

12 And even for the Centre Pompidou example, this seems questionable, as for the bystanders, the choice of a certain distance with respect to the artist and to the other bystanders is also largely guided by the choices the other bystanders make. 
the underlying mechanism holds for all different kinds of language change as well as for other processes of social and cultural change, so its explanatory potential, in the sense of its potential to provide new insights into the reasons why a specific development has taken place, seems limited (if not inexistent). In order to truly explain specific processes of change, it therefore seems necessary to focus on the question why speakers should have introduced and reused a new item.

At the same time, from a theoretical perspective, and more specifically, from a usagebased perspective, it seems questionable that the cumulative process described by Keller really represents a process involving causality in the same sense as in other disciplines. This issue crucially hinges on the definition of language, which involves two fundamentally different aspects, language being a cognitive as well as a social/cultural phenomenon, i.e. language can be defined as a cognitive system, but also as a semiotic system shared by a group of speakers, documented in the totality of their utterances (this latter definition is thus grounded on the conception of language as an ergon, or more precisely, on the various products of linguistic activity that can be observed). If we focus on the latter aspect, there is no causal effect arising from the cumulative process any more, instead it is only the level of abstraction that changes: If language is defined as the abstract system documented in the speakers' utterances, it is tautological to say that language has changed because the utterances have changed. If we approach language as a cognitive phenomenon, in contrast, we can detect a causal aspect in the process of diffusion, as we can assume that changes in the utterances will lead to a change in the way language acquisition and processing takes place (cf. the notion of entrenchment put forward in Cognitive Linguistic approaches; cf. Langacker 1987; Croft 2000: 236; Schmid 2007, Backus/Verhagen 2013). However, we may ask what kind of new insights are provided by this "causal" analysis, as, once again, it describes a general mechanism that holds for all subtypes of language change and does not tell us anything about specific instances of change. This leads us back to the perspective of the individual speakers, and to the question why they should introduce the new item or adopt it from other speakers. Summing up, we can observe that although Keller explicitly claims that he develops a usagebased model of language change, based on the principle of methodological individualism (Keller 1984: 64), his remarks about the diffusion process partly contradict this kind of approach.

Let us now turn to Croft's approach to language change. One of the central claims of his theory (Croft 2000) is that innovation and propagation, which are considered to be the two main processes in language change, have to be explained differently. While functional factors are proposed for the stage of innovation, the subsequent propagation of the innovation is exclusively explained by social factors:

One of the central theses of this book is that there are distinct causal mechanisms that bring about the innovation and the propagation of language change [...]. Functional factors the phonetic and conceptual factors appealed to by functional linguists - are responsible only for innovation, and social factors provide a selection mechanism for propagation. (Croft 2000: 38)

Several points are noteworthy here: Croft strictly separates functional from social factors, but subsumes them both under the concept of causal mechanisms. This can be seen as an advantage of Croft's approach compared to Keller, as he does not try to isolate causal principles and to refer them to specific stages of language change exclusively. At the same time, however, we have seen that the explanatory power of causal analyses of language change in this sense is limited, as they are generally not proposed to make predictions about 
language change, but only to give ex post explanations for changes that have already occurred (and that are thus known to have been successful).

Concerning the functional factors mentioned in the citation, the main explanatory mechanism for innovation is form-function reanalysis, i.e. Croft supposes that language change is initiated by situations where the hearer reanalyzes the speaker's utterance and assigns it a partly different interpretation. ${ }^{13}$ In biological terms (to which Croft constantly refers in his evolutionary approach), this initial step represents an altered replication. ${ }^{14}$ This process is guided by basic cognitive principles, and we can assume that it is normally not perceived by the speakers. This means that innovation is explained by a functional factor, which is grounded in issues of cognitive ease and optimizing the processing efforts within certain limits given by the language system. However, form-function reanalysis cannot be considered to be an intentional factor, as the reanalysis is not guided by the intentions of the individual.

In what sense, then, does form-function reanalysis represent a causal factor? The reanalysis occurring in the hearer's mind when s/he processes the speaker's utterance triggers a subsequent change taking place with the reuse of the form according to the reanalyzed structure. At the same time, however, the reanalysis cannot be predicted, as it has the status of an 'error' (cf. Croft 2000: 186), and the analogy to altered replication in biology suggests that it occurs randomly. Retrospectively, we can thus declare that a certain process of change has been caused by an initial reanalysis, but this would just raise the question of why the reanalysis occurred, so the actual task would be to identify the causal factors leading to formfunction reanalysis. Croft partly addresses this question by reflecting on constraints on the various subtypes of form-function reanalysis (Croft 2000: 126, 130, 134, 140), and he suggests possible ways to test his hypotheses. However, he mainly intends these tests as confirmations that certain contexts do favour reanalysis, but not in the sense of being sufficient conditions which inevitably trigger the new interpretation.

With respect to the stage of selection or propagation, Croft assumes that it is only social factors which are relevant here, that is, the speaker's choice to adopt the innovation or, in contrast, stick to the conventional way of expressing the concept in question is explained exclusively by the different social value of the forms. Again, several issues are raised here. First, Croft uses propagation or, the corresponding term from evolutionary biology, selection, ambiguously, that is, he uses these terms to refer to the global process of diffusion at the level of the speech community as well as to refer to single acts of adoption of the innovation (cf. Winter-Froemel 2011: 136-137, 198-199). A terminological distinction between the two aspects - propagation and adoption (Winter-Froemel 2008: 237-238) - seems indispensable, and, as we have already seen, only the latter aspect identifies factors which can function as explanatory factors for language change from a usage-based perspective.

Nevertheless, the freedom of the individual speaker appears to be quite limited in Croft's approach. We have already seen that Croft assumes that linguistic innovations go back to a form-function reanalysis, which occurs without even being perceived by the speakers.

13 It must be acknowledged, however, that Croft's approach mainly aims at explaining language change in grammar; for many cases of lexical change, in contrast, the mechanism of form-function reanalysis seems much less well applicable, and it seems necessary to add further mechanisms and principles in order to explain the broad variety of lexical change that can be observed.

14 The evolutionary component of Croft's theory raises several questions and problems which cannot be discussed here in detail (cf. Winter-Froemel 2011: 147-152). 
However, this account appears to be too restricted. This becomes clear when we look at innovations that do not arise from unconscious processes such as form-function reanalysis, but at innovations which are introduced with specific pragmatic intentions, etc.; in the latter case, social aspects are immediately relevant already at the stage of innovation.

For the stage of propagation, in turn, Croft assumes that the speakers' options are restricted to a selection between existing variants (but at least, this selection implies a certain degree of free choice, which is completely absent from the stage of innovation such as it is conceived by Croft). Croft thus does not seem to assume a true creativity in the speakers' linguistic activity, which means that the concept of final cause or intentional explanation does not seem applicable here (and, as we have seen in the citation above, Croft strives for the causal mode of explaining language change).

Moreover, for the stage of propagation we can observe that functional aspects continue to be relevant, as the speakers do not only judge the social value of an innovation, but also its functionality in concrete situations of communication. Having this in mind, we could opt for a wider understanding of the term 'functional factors' in order to encompass both functional factors in Croft's sense and the social functions/functionality of innovations ( Croft's social factors).

Summing up, we have seen that the approaches proposed by Keller and Croft share the basic characteristic of proposing two fundamentally different explanatory principles for the stage of innovation and propagation. However, neither of the approaches leaves us with a satisfactory answer to the causal vs. intentional/final debate. Keller's approach does not adequately describe the process of diffusion from a usage-based perspective, and the strict separation between intentional and causal mechanisms seems inadequate, as the process of diffusion also involves single acts of adoption which are guided by certain intentions or a certain functionality of the innovation for the speakers. Concerning Croft, the causal approach that he claims is not convincingly implemented. Moreover, his strict separation between two types of factors of language change also appears to be problematic.

For both approaches, it seems helpful to clearly distinguish between two levels of analysis which can be adopted when studying the diffusion of an innovation: on the one hand, we are dealing here with a genuinely social process, which can be labeled as propagation proper and which translates into frequency data. On the other hand, however, from a usage-based perspective it seems central to study the diffusion also with respect to the single acts of adoption that this process implies (cf. Winter-Froemel 2011: 198-199).

In spite of these potentially problematic issues, the study of both approaches has provided helpful insights into the complexity of our task, as we have seen that processes of language change involve cases of genuinely intentional innovations (such as the standard examples discussed by Keller), but also cases where factors such as processing ease seem to trigger the change (cf. Croft's mechanism of form-function reanalysis). In this sense, their approaches can be seen as being to a certain extent complementary, and it seems possible to integrate them into a larger usage-based framework. In this framework, the label of functional principles or functional explanations appears to be a well-suited label in order to encompass innovations which involve a genuine finality as well as innovations which offer certain cognitive advantages to the speakers, but without necessarily being used by a deliberate choice. 


\section{Conclusion: What can usage-based approaches contribute to a better understanding of language change?}

In order to conclude this brief discussion of previous accounts aiming at explaining language change, we can say that neither causal nor intentional accounts are to be considered as illegitimate ways to approach this phenomenon. Instead, it seems possible to integrate them into a larger framework grounded on the idea that language is a complex manifestation of human activity which can be analyzed according to different methodologies and from different disciplines. However, this means that we should aim at maximal precision concerning the nature as well as the limitations of each disciplinary approach to this phenomenon.

Concerning causal approaches to language change, previous studies have focused either on identifying causal mechanisms in the diffusion of the innovations (cf. Keller) or on cognitive processes (cf. Croft as well as biolinguistic approaches). We have seen that an analysis of diffusion processes in causal terms is problematic, insofar we cannot achieve predictability in the hard sense. What can be achieved is to identify general patterns of diffusion; these, however, do not provide new insights into specific processes of change. Moreover, it has to be assumed that the changes have already occurred, that is, the diffusion patterns are analyzed ex post.

For the approaches oriented towards cognitive processes in language change, it seems possible to study cognitive aspects of language processing which might lead to innovation and change. However, this approach requires a certain scientific methodology (cf. e.g. neurolinguistic studies), and it adopts a specific view of language, as the speakers' linguistic activity is studied without considering the individual's liberty to make certain choices (think of e.g. priming experiments where speakers' linguistic behaviour is shown to be influenced by certain primes that are presented to the speakers without their being aware of it). We cannot decide here whether such a conception is adequate in principle; however, what we can say is that is does not correspond to - at least, not entirely - the way the speakers themselves perceive their linguistic behaviour. In order to provide a satisfactory and comprehensive account of the speakers' linguistic activity and language change, it seems necessary to also take into account the speakers' strategic choices alongside subconscious mental processes. And this means that the notion of finality keeps its full authority in order to account for the multifaceted phenomenon of language change.

Such a view also ties in with the observation that we can retrospectively "explain" that for a certain development, speakers have given priority to a certain functional factor, but this reasoning cannot be understood in terms of predictability in a strict sense. What we can at most achieve here are probabilistic statements. Looking at the speakers' intentions and at final aspects of language change, we can identify factors supporting the use of one form over another; nevertheless, there is a necessary and insuperable tension between different groups of factors. This establishes a constant dynamic, but also means that every factor or potential advantage can be overridden by others. For example, forms which are relatively difficult to process and which are in this respect "inconvenient" may offer the communicative advantage of potentially triggering specific pragmatic effects, leading to a greater communicative success (e.g. being interpreted as signs of expressivity). The tension between the different factors renders teleological accounts questionable in principle. At the same time, however, it opens up the possibility that changes can be introduced and that language is continuously recreated by the speakers' linguistic activity. 
On the whole, the potential of a usage-based approach for language and language change is thereby confirmed. Independent of the causal vs. intentional/final debate, a fundamental requirement for explanations of language change is that they have to be grounded on the level of the individual speakers and their utterances, on which we can identify intentional factors such as the ones studied by Keller as well as functional factors such as the ones studied by Croft (e.g. cognitive ease). What is more, it seems fully legitimate to include also the speakers' perspective in the sense of a folk linguistic approach. That is, the speakers' attitudes towards specific linguistic items also represent a factor which potentially influences language change (even if, of course, language change might not take place in a way which directly matches the speakers' primary intentions, cf. the cases of Mandeville's paradox discussed in section 3).

A domain where the potential of such an approach becomes particularly clear is the process of diffusion. As we have seen in section 2, the S-curve model in its standard interpretation does not follow a usage-based approach; however, grounded on the main assumption of this model that there are different stages within the process of diffusion, we can ask how these stages are qualitatively interpreted by the speakers. Usage-based approaches thus offer a complementary perspective on the diffusion of lexical innovations which is not based on frequency counts of single items of the lexicon, but focuses on the speakers' perspective and on the pragmatic/social value of the innovations. In this way, instead of the quantitative stance of the traditional interpretation of the S-curve model, new insights can be gained from a qualitative approach. The criterion of frequency (which is commonly conceived as reflecting the degree of conventionalization of a certain form in language) is thus replaced by the concept of entrenchment (Langacker 1987; Croft 2000: 236; Schmid 2007, Backus/Verhagen 2013), which expresses the degree to which a certain form is conventionalized in the speakers' minds. Moreover, it can be shown that new linguistic forms bear varying degrees of markedness and therefore convey different pragmatic effects in various stages of their diffusion (cf. Levinson 2000).

Concerning the various explanatory factors and the dynamics arising from the tension between them, we can finally ask how these factors can be systematized. We have critically discussed and eventually discarded Keller's distinction between intentional and causal mechanisms. Croft's strict separation of functional and social aspects, in contrast, points at two fundamental aspects which relate to two aspects of language and communication discussed in section 4: On the one hand, language represents a cognitive phenomenon, and on the other hand, a social or cultural phenomenon. Therefore, from a usage-based perspective, if we study the single acts of speakers' linguistic activity we have to address issues of cognition as well as communication. That is, cognition and communication define two basic dimensions along which linguistic forms can be evaluated from a usage-based perspective, assessing their communicative efficiency and cognitive functionality.

Furthermore, analyzing these two aspects in concrete situations of speaker-hearer interaction, we can ultimately lead back all explanatory factors to cognitive aspects, as communicative aspects such as e.g. the social hierarchy between the communication partners etc. only play a role here if they are internalized by the speaker and hearer. An approach which could provide very interesting perspectives for further research in this direction is, in my view, Coseriu's comprehensive theory of context types ("Umfelder" in his terminology; cf. Coseriu 1955-56) which has been taken up and been partly reworked by Aschenberg (1999). It would be interesting to investigate how the various types of contexts can be reconsidered from a cognitive perspective, i.e. how they can be interpreted as "corpuses of knowledge" in the speakers' minds (cf. Winter-Froemel, in press a) and how this line of research could be 
brought together with notions that have been recently proposed in the framework of Cognitive Linguistics, e.g. salience (cf. among others the Graded Salience Hypothesis; Giora 2002, 2003) and entrenchment. Again, such an approach offers a valuable route to overcome the traditional controversy of causal vs. intentional/final accounts and strive for a comprehensive framework that integrates conscious as well as subconscious aspects of language change, quantitative analyses as well as qualitative investigations about the speakers' choices in their linguistic activity.

\section{References}

Aristotle, Physics. Written 350 B.C.E. Translated by R. P. Hardie/R. K. Gaye. http://classics.mit.edu/Aristotle/physics.2.ii.html (last accessed 16.07.2013).

Aschenberg, Heidi (1999): Kontexte in Texten. Umfeldtheorie und literarischer Situationsaufbau. Tübingen: Niemeyer.

Backus, Ad/Verhagen, Veronique (2013): "Does usage-based linguistics force a rethinking of sociolinguistics? The case of individual variation". Paper presented at ICLC-12, Edmonton, Alberta, 23-28 June 2013.

Barlow, Michael/Kemmer, Suzanne (eds.): Usage-Based Models of Language. Stanford: CSLI Publications.

Blank, Andreas (1997): Prinzipien des lexikalischen Bedeutungswandels am Beispiel der romanischen Sprachen. Tübingen: Niemeyer (= Beihefte zur Zeitschrift für romanische Philologie, 285).

Chomsky, Noam (2004): "Biolinguistics and the Human Capacity [Delivered at MTA, Budapest, 17.05.2004]", <http://www.chomsky.info/talks/20040517.htm> (last accessed 11.07.2013).

Chomsky, Noam (2005): “Three Factors in Language Design”, in: Linguistic Inquiry 36/1, 122.

Coseriu, Eugenio (1955-56): "Determinación y entorno", in: Romanistisches Jahrbuch 7, 29 54.

Coseriu, Eugenio (1958): Sincronía, diacronía e historia. El problema del cambio lingüístico. Montevideo: Universidad de la República (Reimpresión fotomecánica, Tübingen 1969; German translation: Synchronie, Diachronie und Geschichte. Das Problem des Sprachwandels. München: Wilhelm Fink 1974).

Coseriu, Eugenio (1983): „Linguistic Change Does Not Exist“", in: Linguistica nuova ed antica 1, 51-63.

Croft, William (2000): Explaining Language Change. An Evolutionary Approach. Essex: Pearson Education Limited.

Detges, Ulrich (2001): Grammatikalisierung. Eine kognitiv-pragmatische Theorie, dargestellt am Beispiel romanischer und anderer Sprachen. Habilitation thesis, University of Tübingen.

Di Sciullo, Anna Maria et al. (2010): "The Biological Nature of Human Language", in: Biolinguistics 4: 4-34.

Di Sciullo, Anna Maria/Boeckx, Cedric (eds.) (2011): The Biolinguistic Enterprise. New Perspectives on the Evolution and Nature of the Human Language Faculty. Oxford: Oxford University Press. 
Enfield, Nick J. (2003): Linguistic epidemiology: Semantics and grammar of language contact in mainland Southeast Asia. London: Routledge Curzon.

Engels, Eve-Marie (2007): Charles Darwin. München: C. H. Beck.

EWDS = Kluge, Friedrich $\left({ }^{24} 2002\right)$ : Etymologisches Wörterbuch der deutschen Sprache. Bearb. von Elmar Seebold. Berlin/New York: de Gruyter.

Falcon, Andrea (2012): “Aristotle on Causality", in: Zalta, Edward N. (ed.): The Stanford Encyclopedia of Philosophy. http://plato.stanford.edu/archives/win2012/entries/aristotlecausality/ (01.08.2013).

Farrar, Kimberley (1999): "Explanations for Word Order Change in Modern German", in: Zeitschrift für Dialektologie und Linguistik 66/1, 1-30.

Fleischer, Jürg/Simon, Horst J. (eds.) (2013): Sprachwandelvergleich - Comparing Diachronies. Berlin/New York: de Gruyter.

Giora, Rachel (2002): “Literal vs. figurative language: Different or equal?", in: Journal of Pragmatics 34: 487-506.

Giora, Rachel (2003): On our mind: Salience, context, and figurative language. New York: Oxford University Press.

Givón, Talmy (2002): Bio-Linguistics. The Santa Barbara Lectures. Amsterdam: Benjamins.

Heine, Bernd/Kuteva, Tania (2002): World Lexicon of grammaticalization. Cambridge: Cambridge University Press.

Hilty, Gerold (1980): "Bedeutung als Semstruktur", in: Vox Romanica 30, 242-263.

Hull, David L. (1988): Science as a Process. An Evolutionary Account of the Social and Conceptual Development of Science. Chicago, London: The University of Chicago Press.

Itkonen, Esa (2011): “On Coseriu's legacy”, in: Energeia 3, 1-29.

Jenkins, Lyle (2000): Biolinguistics. Exploring the Biology of Language. Cambridge: Cambridge University Press.

Jenkins, Lyle (ed.) (2004): Variation and Universals in Biolinguistics. Amsterdam: Elsevier.

Johnson, Lawrence (1976): “A Rate of Change Index for Language”, in: Language in Society 5/2: 165-172.

Kabatek, Johannes (1996): Die Sprecher als Linguisten. Interferenz- und Sprachwandelphänomene dargestellt am Galicischen der Gegenwart. Tübingen: Niemeyer.

Keller, Rudi (1984): "Bemerkungen zur Theorie des sprachlichen Wandels“, in: Zeitschrift für germanistische Linguistik 12, 63-81.

Keller, Rudi (1994): Sprachwandel. Von der unsichtbaren Hand in der Sprache. 1st edn. 1990. Tübingen: Francke (English translation: On Language Change. The invisible hand in language. London: Routledge 1994).

Keller, Rudi (1995): “The epistemic weil”, in: Stein, Dieter/Wright, Susan (eds.): Subjectivity and subjectivisation. Linguistic perspectives. Cambridge: Cambridge University Press, 1630 .

Kipling, Rudyard (1987 [1902]): Just So Stories. London: Penguin.

Koch, Peter/Oesterreicher, Wulf (1990): Gesprochene Sprache in der Romania: Französisch, Italienisch, Spanisch. Tübingen: Niemeyer (= Romanistische Arbeitshefte, 31).

Kroch, Anthony (1989): "Reflexes of grammar in patterns of language change", in: Language Variation and Change 1, 199-244.

Labov, William (2010 [1994]): Principles of Linguistic Change. Volume 1: Internal Factors. Oxford/Cambridge, Mass.: Blackwell (Language in Society 20). 
Langacker, Ronald W. (1987): Foundations of cognitive grammar. Vol. I: Theoretical prerequisites. Stanford: Stanford University Press.

Lass, Roger (1980): On Explaining Language Change. Cambridge: Cambridge University Press.

Lenneberg, Eric H. (1967): Biological Foundations of Language. New York: John Wiley \& Sons.

Lüdtke, Helmut (1980): "Sprachwandel als universales Phänomen", in: Lüdtke, Helmut (ed.): Kommunikationstheoretische Grundlagen des Sprachwandels. Berlin/New York: de Gruyter, 1-19.

Müller, Horst M. (1990): Sprache und Evolution. Grundlagen der Evolution und Ansätze einer evolutionstheoretischen Sprachwissenschaft. Berlin, New York: de Gruyter.

Newmeyer, Frederick J. (1991): "Functional Explanation in Linguistics and the Origins of Language", in: Language \& Communication 11, 3-28.

OED = Oxford English Dictionary. Oxford: Oxford University Press, 2013. http://www.oed.com/ (last accessed: 08.10.2013).

Oesterreicher, Wulf (1979): Sprachtheorie und Theorie der Sprachwissenschaft. Heidelberg: Winter.

Oesterreicher, Wulf (1988): "Sprechtätigkeit, Einzelsprache, Diskurs und vier Dimensionen der Sprachvarietät", in: Albrecht, Jörn/Lüdtke, Jens/Thun, Harald (eds.): Energeia und Ergon. Sprachliche Variation, Sprachgeschichte, Sprachtypologie. Studia in honorem Eugenio Coseriu. 3 vols. Tübingen: Narr, vol. 2, 355-386.

Onysko, Alexander/Winter-Froemel, Esme (2011): "Necessary loans - luxury loans? Exploring the pragmatic dimension of borrowing", in: Journal of Pragmatics 43, 15501567.

Piattelli-Palmarini, Massimo/Uriagereka, Juan/Salaburu, Pello (eds.) (2009): Of Minds and Language. A Dialogue with Noam Chomsky in the Basque Country. Oxford: Oxford University Press.

Rogers, Everett M. (1995 [1962]): Diffusion of innovations. Fourth edn. New York, London, Toronto: The Free Press.

Saussure, Ferdinand de (1969 [1916]): Cours de linguistique générale. Publié par Charles Bally et Albert Sechehaye. Paris: Payot.

Schlieben-Lange, Brigitte (1998): "Alterität als sprachtheoretisches Konzept", in: Zeitschrift für Literaturwissenschaft und Linguistik 110, 41-57.

Schmid, Hans-Jörg (2007): "Entrenchment, Salience, and Basic Levels", in: Geeraerts, Dirk/Cuyckens, Hubert (eds.): The Oxford Handbook of Cognitive Linguistics. Oxford: Oxford University Press, 117-138.

Traugott, Elizabeth Closs/Dasher, Richard B. (2002): Regularity in Semantic Change. Cambridge: Cambridge University Press.

Traugott, Elizabeth Closs/König, Ekkehard (1991): "The Semantics-Pragmatics of Grammaticalization Revisited", in: Traugott, Elizabeth Closs/Heine, Bernd (eds.): Approaches to Grammaticalization. Vol. 1: Focus on Theoretical and Methodological Issues (= Typological Studies in Language, 19.1.). Amsterdam, Philadelphia: John Benjamins, 189-218.

Winter-Froemel, Esme (2008): “Towards a Comprehensive View of Language Change. Three Recent Evolutionary Approaches", in: Detges, Ulrich/Waltereit, Richard (eds.): The Paradox of Grammatical Change. Perspectives from Romance. Amsterdam: Benjamins (= Current Issues in Linguistic Theory, 293), 215-250. 
Winter-Froemel, Esme (2010): “Les people, les pipoles, les pipeuls: Variance in loanword integration", in: PhiN 53, 62-92 [http://web.fu-berlin.de/phin/].

Winter-Froemel, Esme (2011): Entlehnung in der Kommunikation und im Sprachwandel. Theorie und Analysen zum Französischen. Berlin, Boston: de Gruyter (Beihefte zur Zeitschrift für romanische Philologie, 360).

Winter-Froemel, Esme (2012): "The diffusion of lexical innovations in French: Critical reflections on the S-curve hypothesis", in: Pre-Proceedings of the International Conference Linguistic Evidence 2012. Empirical, theoretical and computational perspectives. Tübingen, $9^{\text {th }}$ to $11^{\text {th }}$ of February 2012. University of Tübingen, Germany, 137-140.

Winter-Froemel, Esme (in press a): "Ambiguität im Sprachgebrauch und im Sprachwandel: Parameter der Analyse diskurs- und systembezogener Fakten”, to appear in: Zeitschrift für französische Sprache und Literatur 123/2.

Winter-Froemel, Esme (in press b): “Ambiguitätsphänomene im Umfeld des Verbs in der Diachronie der romanischen Sprachen", to appear in: Romanistisches Jahrbuch (2012).

Winter-Froemel, Esme/Zirker, Angelika (2010): "Ambiguität in der Sprecher-HörerInteraktion. Linguistische und literaturwissenschaftliche Perspektiven", in: Zeitschrift für Literaturwissenschaft und Linguistik 158, 76-97. 